\title{
VIDA PÚBLICA EN IGLESIAS LATINAS DE ESTADOS UNIDOS: EXPANSIÓN DEL PARADIGMA
}

\author{
DANIEL RAMÍREZ
}

Traducción del inglés

Luis Rodolfo Morán

RESUMEN. Este trabajo cuestiona los paradigmas que se han empleado en el análisis de la iglesia latina en la vida pública estadounidense. Más allá de los índices tradicionales, subraya la solidaridad a nivel micro, redefine lo público al considerar a las congregaciones como una especie de plaza pública y un ámbito transnacional y contempla las prácticas y creencias religiosas propias de la diáspora latina en Estados Unidos, particularmente en la región sureste. Para cumplir su propósito, se recurre lo mismo al análisis de algunos textos religiosos que a la descripción etnográfica.

Palabras clave. Cultura, religión, testimonios ilegales, voz pública, iglesias latinas.

ABSTRACT. This study questions the paradigms used in the analysis of the Latin church in American public life. Beyond traditional indices it underlines the solidarity that exists at the micro level, redefines 'the public' in considering the congregation as a public and transnational space, and considers the religious practices and beliefs of the Latin American diaspora in the United States, particularly in the Southeast. This is achieved through this an analysis of several religious texts as well as ethnographic description.

KEYWORDS. Culture, religion, illegal testimonies, public voice, Latin churches.

"Arizona State University, Tempe. El autor desea expresar su agradecimiento a Eliseo Ramírez, Israel Tapia y Ruth Tapia, al igual que a la fallecida Rosalva Arias de Martínez, Tomás Oceguera, Elías Castillo y Salvador Arias. 


\section{INTRODUCCIÓN}

La Biblia es la bandera de la celeste tierra.

Sus franjas, sus estrellas nos hablan de su amor Ciudad de redimidos, refugio do mi Cristo Comprólo con su sangre a precio de expiación Yo soy un ciudadano de esa ciudad eterna Por fe fui redimido y hoy ciudadano soy Es Cristo el gobernante de esa gloriosa tierra $\mathrm{Y}$ al flotar su bandera anuncia redención JUAN CONCEPCIÓN

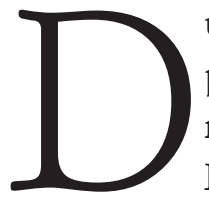
urante el otoño de 1994, mientras la ansiedad se apoderaba de buena parte de la comunidad de inmigrantes en California, la letra del himno escrito por el compositor puertorriqueño Juan Concepción, "La Biblia es la bandera», parecía adquirir, como los cantos espirituales de los esclavos negros en vísperas de ser emancipados, una doble significación. Las personas que me rodeaban - muchas de ellas indocumentadas - enfatizaban, enérgicamente, la declaración del coro acerca de la dignidad celestial y, por ende, terrenal, al mismo tiempo que conservaban un ojo vigilante en espera de la aparición de las camionetas verde claro de la migra y ponían el oído alerta en torno a las noticias acerca de la Propuesta 187. Me sentí impresionado por la subversión metafórica, el significado multivalente y la movilidad de la composición que databa de décadas atrás.

El enérgico vals de Concepción, escrito en el entorno de la experiencia colonial y la diáspora boricua, tocado ampliamente en las iglesias pentecostales chicana, mexicana y centroamericana, nunca entró en el canon de la principal corriente himnológica de los protestantes latinos. ${ }^{1}$ Su rechazo es el reflejo de otras exclusiones: entre ellas, el apartamiento de las congregaciones pentecostales y evangélicas como espacios para el logro de poder político. Sin embargo, en contraste con la himnología dominante, la canción representa una nota ideológica disonante en contra de una ciega lealtad al imaginado Estado-nación y a sus

\footnotetext{
${ }^{1}$ En términos de movilidad, los flujos misioneros y migrantes de los pentecostales latinos llevaron los cantos hacia el sur; aparece en los himnarios de las iglesias apostólicas mexico-estadounidense, mexicana y nicaragüense: Himnos de Consolación, Himnario de Suprema Alabanza a Jesús, Himnario de Suprema Alabanza, Aumentada.
} 
símbolos. El patriotismo puede representar no sólo el último refugio de los malhechores, sino también un impedimento idólatra para un diseño más universal de la humanidad.

El segundo verso del himno de Concepción reinscribe significados que van, por encima de lo nacional, sobre elementos patrióticos familiares: «Sesenta y seis estrellas/ Que hay en la bandera/ Representan los libros/ Que en ella encontrarás/ Sus franjas que son doce/ Sus tribus representan/Y el asta en que ella flota/ El Cordero Pascual». Nótese la reelaboración de los símbolos evidentemente estadounidenses (las barras y las estrellas) en el segundo verso del himno que se canta en México y Centroamérica.

El tercer verso anuncia un momento de reunión universal más allá de las fronteras terrestres: «De todo pueblo y raza/ De toda tribu y lengua/ Se formará una patria/ En la celeste Sión/ Y allí todos reunidos/ Bajo de esa bandera/ Cantaremos las glorias/ De paz y redención». Esos textos religiosos — himnos, coritos, testimonios - nos recuerdan la naturaleza tentativa de los paradigmas de la ciencia social que, con frecuencia, empleamos en nuestro análisis de la religión en la vida pública estadounidense. El estudio debe permanecer elástico, en su definición de la "vida pública», para incluir la amplitud y la profundidad de la vida comunitaria, incluida la vida que se lleva en los márgenes de lo público y en los márgenes entre dos públicos. Debe mirar más allá de los signos tradicionales de la participación pública (por ejemplo, el empadronamiento para el voto, las campañas) para apreciar el alcance de la participación y la solidaridad en los niveles micro y macro. Las iglesias latinas se verían, entonces, como expresiones de la vida pública estadounidense, como los sitios preferidos de la comunidad para el discurso y como plazas públicas de creación propia de las comunidades. Muchos encuentran, inauguran y escuchan aquí que se afirma su voz pública. Para un proletariado marginal en movimiento, las congregaciones latinas sirven no sólo como antesalas de la plaza pública, sino también como santuarios en las que se forjan y sostienen identidades de transición, al tiempo que se fortalecen los vínculos intergeneracionales e intraétnicos. La agencia que se refuerza en un lado de la frontera puede ser, luego, utilizada como palanca para afirmar los derechos y las prerrogativas al otro lado de ella.

Con esta reconfiguración espacial en mente - de la congregación como plaza pública y de la plaza pública como esfera transnacional-, este trabajo busca explorar las prácticas y creencias protestantes latinas en la creciente diáspora latina. El cambio geográfico de las regiones tradicionales de la vida latina encuentra un paralelo en un cambio metodológico: al trasladarse de los análisis de los textos culturales a la descripción etnográfica «densa». Ciertamente, este movimiento interdisciplinario no busca la marcada divergencia de la perspectiva de la ciencia social o de nuestro propio entrenamiento como historiadores sociales; en cambio, intenta complementarlos al señalar caminos previamente descuidados que pueden ser iluminados por enfoques más detallados. 
Este trabajo cuestiona la metanarrativa que data de hace décadas, acerca del pentecostalismo, que hablaba de privación social y económica, de tensión psicosocial así como de limitada liberación. El sociólogo suizo Lalive D’Epinay estableció el marco con la descripción de las iglesias pentecostales chilenas, como réplicas religiosas urbanas de la sociedad rural de la hacienda, en «huelga social» e inútilmente desvinculadas — dentro de enclaves apolíticos - de la participación social y política significativa (D'Epinay, 1969). ${ }^{2}$ Al yuxtaponerse con las impetuosas posibilidades del socialismo, el soporífero pentecostalismo amenazaba con confundir los proyectos proletarios de liberación —económica así como política-a lo largo y ancho del hemisferio. Los eventos subsecuentes en Chile, en especial la cooptación de los líderes de la iglesia protestante por Augusto Pinochet al inicio de su golpe de Estado contra Salvador Allende, en 1973, parecían confirmar la temible advertencia de D'Epinay.

Dos décadas más tarde, el pesimismo resurgiría en el estudio de Lesley Gill sobre las trabajadoras domésticas aymara en La Paz, Bolivia, a quienes encontró políticamente alienadas y, por tanto, en específico susceptibles de la retórica escapista y moralizadora que se escuchaba en los púlpitos pentecostales (Gill, 1994). Para Gill, el pentecostalismo se había insertado, en la clase trabajadora boliviana, en un momento estratégico de frustración económica y política. En vez de dirigirse al salón sindical las tardes del domingo, para dar consistencia a Marx, a las mujeres aymara podía encontrárseles hablando, golpeando tamborcillos y gritando antifonales aleluyas a machistas oradores aporreadores de la Biblia. Paradójicamente, para Gill, pasaban horas que podrían dedicarse a la concientización de la fuerza de trabajo, en espiar y entrampar a los hombres reformados (del machismo) dentro de los templos que ellas, en cambio, habían ocupado por buena parte de día. Una luz soporífera, con algunas posibilidades maritales mejoradas.

Más al norte, el sociólogo Abelino Martínez concluía que el discurso ultramundano del pentecostalismo nicaragüense («oferta y demanda de salvación») y la práctica social conservadora, al ser de naturaleza eminentemente religiosa, no «estimulaba la politización de sus miembros, sino que perpetuaba su indiferencia [política]» (Martínez, 1989). El sociólogo costarricense Jaime Valverde era menos misericordioso con las sectas pentecostales en su país. Para Valverde, la marcada dicotomía del pentecostalismo, entre espíritu/vida espiritual y cuerpo/política,

\footnotetext{
${ }^{2}$ La teoría de D’Epinay de la «huelga social» se basaba en la de Max Weber y su "privación relativa» que, a su vez, fue desarrollada por otros sociólogos para incluir las dimensiones económica, social y psicológica (Weber, 1970; Glock, 1958, y Durkheim, 1970).
} 
generaba una falsa conciencia en el proletariado. El discurso teológico resultante coincidía con el orden social dado y sus reglas del juego impuestas, manteniendo, así, a ambas. En vez de unirse a la lucha de clase, quienes se adherían al pentecostalismo veían a la crisis económica y social reinante como cumplimiento de la profecía bíblica; por ende, adoptaban actitudes sumisas hacia su opresión económica y, con ello, garantizaban su continuación (Valverde, 1990).

La extrapolación, hacia los pentecostales latinos en Estados Unidos, de los hallazgos derivados en diversos estudios del pentecostalismo latinoamericano se debe, en mucho, a la falta de estudios similares en Estados Unidos, al igual que a la ausencia de las variables religiosas en los estudios políticos y de otras ciencias sociales referidos a los latinos en el citado país. Incluso una atención mínima a éstas parece aditiva; las variables religiosas se han incluido en los instrumentos de encuesta diseñados para captar dimensiones más tradicionales del comportamiento político y social de los latinos (entre ellos, la filiación partidista, la historia electoral, la filiación religiosa). De ahí que la encuesta pionera de 1992, la Latino National Political Survey (LNPS), clasificara a quienes respondieron (2,817 latinos -mexico-estadounidenses, puertorriqueños y cubanos-y 456 blancos no hispanos) en tan sólo cinco variables religiosas: 1) preferencia religiosa (católico, protestante, judío, sin preferencia, algo distinto); 2) filiación denominacional (se ofrecían varias opciones protestantes); 3) experiencia de «renacimiento»; 4) guía religiosa, y 5) asistencia a servicios religiosos. Los pocos reactivos religiosos (de un total de casi 200) tenían, como consecuencia, una utilidad igualmente baja de los datos religiosos, aun cuando ello se combinara con las respuestas de las actividades y filiaciones voluntarias así como los temas políticos de "botón rojo». La conclusión de los autores, en el sentido de que los mexico-estadounidenses nacidos en Estados Unidos «no están particularmente inclinados a indicar que la religión influya significativamente en sus vidas diarias», parece poco sorprendente, en especial porque, el 59\% de quienes respondieron, confesaron una asistencia de cero o mínima a los servicios religiosos — «unas cuantas veces al año»— (De la Garza, DeSipio, Garcia, Garcia y Falcon, 1992).

La misma cohorte de investigación realizó una encuesta complementaria, el Latino Political Ethnography Project (LPEP), con la intención de detallar «la participación política de las bases en la política electoral convencional» (De la Garza y DeSipio, 1993). Estableciendo 1999 como año base, los investigadores se distribuyeron en cinco de los más grandes y antiguos barrios de latinos en Estados Unidos: Boyle Heights, en el este de Los Ángeles; Pilsen, en Chicago; Magnolia, en Houston; el Barrio, en el este de Harlem, y la Calle Ocho, en Miami. Mientras que muchos de los interrogados y participantes, en los grupos de foco de las comunidades predominantemente méxico-estadounidenses, subrayaron la importancia de las parroquias católicas como base para el empadronamiento de votantes y las reuniones para organización comunitaria (por ejemplo, contra los proyectos de construcción de cárceles e instalaciones para el manejo de desechos), una vez más los investigadores no trascendieron estas señales de participación pública. Sólo uno de 
los trece reactivos centrales planteaba, a los interrogados, que mencionaran explícitamente la participación en la iglesia, y ello de manera limitada: «żParticipan las organizaciones establecidas en el barrio (iglesias, clubes, locales sindicales) en estas actividades [electorales] ?» Los dos reactivos siguientes preguntaban acerca de los organizadores y quienes asistían (De la Garza y DeSipio, 1993). El enfoque de ambos estudios, acerca de los comportamientos y actitudes políticas de los ciudadanos estadounidenses, apenas rozaba la compleja red de relaciones que vincula a muchos de éstos con los inmigrantes permanentes, temporales e indocumentados.

\section{NUEVOS PARADIGMAS}

La frustración y desencanto del último cuarto de siglo, con respecto a los proyectos de liberación teológica y política, desataron un replanteamiento de las preguntas, y respuestas, prevenidas por D'Epinay y colaboradores. Varios estudios antropológicos se situaron en espacios diferenciados así como específicos y, desde estos particulares puntos, cuestionaron la descripción universalizante de los sociólogos al ofrecer, en concordancia con su método etnográfico subdisciplinario, análisis más a fondo de las dinámicas de conversión en el nivel básico de la identidad de género y étnica. Por nombrar a tres de ellos, Elizabeth Brusco describió el fomento de la conversión, por las mujeres colombianas, como una «acción colectiva femenina» dirigida a la "reforma del machismo» (Brusco, 1995). John Burdick encontró que las mujeres negras pentecostales, implícita y explícitamente, habían dado la vuelta a la opresiva jerarquía estética racial de la sociedad brasileña, por medio de una redefinición contracultural de la belleza femenina (Burdick, 1998); por su parte, Rosalía Hernández develaría identidades múltiples en las fronteras (Chiapas-Guatemala) de los mam-mayas, muchos de los cuales daban el crédito a la iglesia presbiteriana por proveerles santuarios, lingüísticos y culturales, durante épocas anteriores de opresión cultural por el gobierno (Hernández, 2001).

La suma de éstos y otros hallazgos representaba un desafío etnográfico a la tesis de D'Epinay, sobre la alienación, e invitaba a realizar investigación abierta acerca del proceso de la conversión y la praxis religiosas, así como a la participación social. Es importante, dadas sus estrategias metodológicas (entrevistas a profundidad, observación participante), que los estudios evidenciaran una disposición a escuchar, cuidadosamente, la versión de la historia de sus consultados, además de reconocerles una mayor dimensión a su agencia y su autorepresentación.

\section{CULTURA Y RELIGIÓN COMO POLÍTICA}

La expansión metodológica propuesta toma, como punto de partida, recientes estudios innovadores, entre otros, al del analista político Jesús Martínez acerca de 
Los Tigres del Norte. En su análisis de la discografía y ejecución musical de Los Tigres del Norte - el grupo más popular de música norteña en Estados Unidos y México, que ha vivido en San José, California, desde fines de los años sesenta-, Martínez argumenta que estos trovadores de la experiencia migratoria han dado una voz pública a millones de compatriotas en su celebración de un movimiento trasgresor - Que vivan los mojados - , historias de embaucadores - Contrabando y traición-, pueblos sin ley y amores perdidos —Plaza Garibaldi-, la topografía mexicana - Bajo el cielo de Morelia - e incluso del activismo chicano - Cuando gime la raza- (Martínez, 1993). Martínez da cuerpo, a su análisis, con una descripción etnográfica densa de un concierto-baile en el nuevo y cavernoso Centro de Convenciones de San José. El poder de convocatoria de Los Tigres reunió a siete mil personas, muchas de ellas provenientes de la fuerza laboral de afanadoras del Valle del Silicón -y muchos, probablemente, se involucraron después en la exitosa organización de los trabajadores- (Zlolniski, 1998). Visto a través de este prisma, el concierto de Los Tigres equivalía a un evento público, en especial bajo la rampante sombra de la Propuesta 187. La cultura como política.

La creativa apreciación de Martínez acerca de Los Tigres resultó profética. En 2000, el grupo, que había ganado el premio Grammy, estableció la Fundación de Los Tigres del Norte en el campus Los Ángeles de la Universidad de California, dotando generosamente al Centro de Estudios Chicanos (Chicano Studies Research Center) con recursos para «el estudio, preservación y difusión de la música folklórica en español». La notable recuperación de la voz pública comenzó con la transmisión digital de la colección "Arhoolie Frontera», consistente en cinco mil discos fonográficos producidos (en su mayor parte) en Estados Unidos, entre 1910 y 1950 (http://www.sscnet.ucla.edu/csrc/tigres1.html).

El enfoque de Martínez también tenía un paralelo en análisis pioneros de la cultura musical fronteriza, los cuales se llevaban a cabo en el suroeste de Estados Unidos. El estudio seminal del folklore, realizado por Américo Paredes, sobre los corridos de la frontera y el tratamiento más explícitamente etnomusical que hace Manuel Peña de la música texana de conjunto, apuntaban a formas alternativas de discutir las comunidades subordinadas, su articulación pública del poder y los enfrentamientos (internos así como externos) en torno a la identidad por medio de la práctica y la estética de la cultura musical (Paredes, 1985). ${ }^{3}$

Sin lugar a dudas, ninguno de estos practicantes de la música ha desarrollado críticas sistemáticas de las desigualdades sociales o algún programa de liberación. Después de todo, son poetas. Tampoco lo han hecho la mayor parte de los

\footnotetext{
${ }^{3}$ Para un estudio etnomusicológico paralelo, en una situación subalterna completamente diferente (apartheid), véase Erlmann (1996), y para un análisis literario de los corridos fronterizos, véase Herrera-Sobek (1993).
} 
practicantes de la religión. Los estudiantes de ambos campos (de la música y la religión populares) se han visto desafiados a teorizar, de manera creativa, acerca de la relación recíproca entre práctica y teoría. Es precisamente, en este nivel de lo popular, en donde varios teólogos latinos han trabajado para articular las visiones del compromiso religioso con la solidaridad, la liberación y la justicia. La huerta teológica, orgánico-latina, está rindiendo muchos frutos teóricos, entre ellos, la obra del liberacionista católico Roberto Goizeuta, Caminemos con Jesús; la del pionero teólogo católico Virgilio Elizondo, Galilean Journey, y los pentecostales Eldin Villafañe y Benjamín Valentín, Liberating Spirit y Mapping Public Theology; además de una multitud de ofertas de los teólogos mujeristas. Por citar sólo un ejemplo, basado en su estudio de la práctica popular católica, el teólogo Roberto Goizueta ha articulado una compleja "praxis liberadora» y una «teología del acompañamiento» que permanecen «enraizadas y a la vez atentas a la experiencia particular de los hispanos en Estados Unidos como experiencia estética, ético-política, racional y preferida» (Goizueta, 1998). Los estudiosos de la participación cívica de las iglesias latinas harían bien en considerar esta aproximación más orgánica.

Mientras que las derivaciones y los movimientos de baile de la música norteña estimulaban, a Martínez a repensar las medidas tradicionales del comportamiento político, a poca distancia de él un equipo de investigadores, encabezados por los antropólogos Renato Rosaldo y William Flores, se encontraban ocupados encuestando a los residentes del área acerca de su noción de «ciudadanía cultural». Los consultaban acerca de los espacios en los que se sentían mejor recibidos y observaban las "prácticas sociales que, en su conjunto, reclaman y establecen un espacio social delimitado para los latinos en este país» (Flores y Benmayor, 1997). El diseño de investigación era engañosamente simple: estudiar «el proceso de 'afirmación', como la propia comunidad define sus intereses, sus solidaridades recíprocas, su propio espacio y su membresía — quién es y quién no es parte de su 'ciudadanía'—. Enfocado en cuatro ubicaciones (una escuela media en el este de San José, un gran mercado de remates al aire libre, un parque público y un hospital comunitario) además de un cierto número de celebraciones públicas (5 de mayo, día de San Juan), Rosaldo y colaboradores describieron una «nueva política de la ciudadanía», a través de la cual «la gente en las comunidades subordinadas lucha por lograr un reconocimiento político (enfranchisement) pleno y [...] busca el bienestar, la dignidad y el respeto en sus vidas cotidianas ordinarias» (énfasis de nuestro). Multiplicado miles de veces, el ejercicio de esa ciudadanía en el nivel micro puede presentar ramificaciones en el nivel macro, o sea, «una renegociación del contrato social básico de Estados Unidos» (Rosaldo y Flores, 1997).

TESTIMONIOS ILEGALES: REPENSAR LA VOZ PÚBLICA

Los estudios antes mencionados contribuyen a iluminar, bajo una perspectiva di- 
ferente, el comportamiento de las comunidades de fe de los latinos en Estados Unidos, en especial durante los periodos de hostilidad xenófoba. Han configurado nuestra redacción de las narrativas transgresoras, los testimonios ilegales, término que utilizamos para las narraciones públicas y semipúblicas de los cruces fronterizos «ilegales» por miembros de las congregaciones pentecostales latinas. Estos testimonios ejemplifican, suponemos, buena parte de las demandas de ciudadanía y las estrategias que resaltan Martínez, Rosaldo y otros. Además, cuando se acompañan por el intercambio de bienes más materiales (vivienda, empleo, «ofrendas de amor», consejo, contactos y otros elementos de los procesos sociales esbozados por Massey y Durand), o cuando se sitúan en el marco de la liturgia pentecostal, tales testimonios simbólicos articulan una voz pública a favor de una comunidad que, en otras visiones, se piensa como apolítica y carente de voz.

Muchas de estas narrativas clandestinas describen una zona fronteriza conflictiva, en donde un Estado-nación ha empujado, a los peregrinos transgresores, hacia un terreno peligroso en un intento cínico de separar a las mujeres y los niños del flujo de inmigrantes indocumentados. Desde la puesta en práctica de las operaciones Hold-the-Line (E1 Paso), Gatekeeper (San Diego) y Río Grande, han sido cientos quienes han terminado como cadáveres deshidratados, congelados, ahogados o torturados, muchos de ellos en calidad de cuerpos anónimos. ${ }^{4} \mathrm{No}$ obstante, en muchos de estos testimonios ilegales, la zona se ha transformado en un espacio de solidaridad fraternal. Las parábolas del Evangelio del cordero perdido y de los buenos samaritanos acuden, con facilidad, a las mentes de los muchos hermanos -incluidos los fieles nacidos en Estados Unidos- que celebran las nuevas del arribo seguro de los seres amados. A los agentes de la Patrulla Fronteriza se les asignan pequeños roles como implacables perseguidores, cuya moralidad se sitúa apenas por encima de la moralidad de los ladrones del camino de Jericó. Las advertencias legalistas del fariseo, situado en la comodidad, no tienen utilidad en esta zona gris del compromiso ético. La callada solidaridad ejercida dentro de las congregaciones multigeneracionales (y con distintos estatus legales) expande el paradigma político o, simplemente, nos recuerda que la política sigue siendo el arte de lo posible. Aunque los pentecostales latinos no hayan sido invitados a la mesa de discusión de las políticas migratorias, ciertamente no han mostrado un acuerdo sumiso ante sus decisiones ni se han conformado con sus migajas. Bastarán unos cuantos ejemplos.

Algunos testimonios se asemejan a sagradas historias de sagacidad. Es frecuente que confundidos agentes de la Patrulla Fronteriza sirvan como miserables antagonistas, patiños del embaucador:

${ }^{4}$ El estudio binacional más exhaustivo situaba, conservadoramente, la cifra de muertes en 1,600, entre 1993 y 1997. Véase Eschbach, Hagan, Rodríguez, Hernández-León y Bailey (1999). 
Al conducir por la carretera interestatal número 5 desde San Diego, bajo un cielo nublado, el coyote notó que sus pollitas de edad madura tenían ese inequívoco aspecto de los aleluyas. Las delataban su ropa conservadora, sus caras sin maquillaje y el pelo largo y recogido. "Parece que son cristianas, verdad?" "Sí, Señor», respondieron nerviosas. "Pos pónganse a orar pa' que venga la lluvia. Cuando hay Iluvia, se meten los agentes a la estación de San Onofre, y dejan de revisar los carros». Echando mano de sus reservas de energía, la hermana Godínez y su compañera unieron las manos y oraron con las palabras del viejo corito: "iManda la lluvia, Señor!». Al pasar por San Onofre y hacia Los Ángeles y el templo y la parentela, los únicos mojados eran los agentes de la Patrulla Fronteriza que buscaban refugio ante la tormenta. ${ }^{5}$

La hermana Godínez y su compañera sabían que a su llegada a Tijuana debían dirigirse a un cierto hotel de esa ciudad. Les serviría como un nodo fronterizo entre su congregación de origen, en la Ciudad de Guatemala, y la congregación hermana en Los Ángeles. Peregrinos anteriores, compañeros de la congregación, incluido el hijo de la hermana Godínez, ya habían marcado el camino.

Durante el último tramo del viaje, un documento específico probablemente cobró una mayor importancia a medida que la pareja se acercaba a su destino, se trataba de una carta de recomendación de su congregación de origen. Imposibilitados para lograr la admisión legal en el moderno Estado-nación, muchos peregrinos recurren a este antiguo género literario, el que da fe de un historial de buen carácter y fiel servicio cristiano. Las cartas de las iglesias apostólicas de México y Centroamérica, con frecuencia, incluyen una frase clave: «le ruego que reciba a mi recomendado como es costumbre entre nosotros ("No os olvidéis de practicar la hospitalidad, ya que de este modo algunos han atendido a los ángeles sin darse cuenta', Hebreos 13:2), que le extiendan la mano derecha del compañerismo y que le ayuden con el consejo y la orientación que le sean necesarios» (énfasis nuestro).

La lectura pública de la Carta de recomendación en la asamblea de la congregación receptora transforma el documento, de ser un documento ordinario, en una poderosa credencial. De tal modo, un inmigrante cuyo trabajo y valía personal como campesino, jardinero, empleada doméstica o palotero se tiene en baja estima (y se compensa escasamente) por una distanciada sociedad capitalista durante el día (o lo que dura el turno de trabajo en la huerta) recupera al tiempo que se le asigna una buena dosis de autoestima y valía personal, cuando se reúne con sus hermanos en Cristo y éstos le confían los diversos oficios junto con los proyectos de

${ }^{5}$ Las diversas narrativas fueron compiladas y redactadas, por primera vez, para una columna compartida entre los diarios afiliados al Pacific News Service cuando se generó la «Propuesta 187» (Ramírez, 1995). Los informantes y las congregaciones permanecieron anónimos en cuanto a su autoría. 
la congregación. Para las congregaciones latinas, lo simbólico, al estar investido de una profunda significación teológica - la cual se le rearticula miles de veces en los rituales de bienvenida (incluida la himnología temática)—, incide tanto en la vida de la comunidad como lo material, lo macroeconómico y lo macropolítico.

Cuando se hace necesario, la banda de peregrinos ofrece una protección anónima frente a la pesada y caprichosa mano de las autoridades. Esa protección puede significar un tiempo valioso y generar un espacio de respiro para la importante reconstrucción personal:

En 1994, un miembro de la congregación del área de la Bahía de San Francisco fue atropellado y muerto por un automóvil a alta velocidad mientras se trasladaba en bicicleta a su trabajo. El hermano Efrén, un inmigrante indocumentado de 52 años de edad, cuyo hábito etílico de 32 años había devastado su vida, su familia y su cuerpo, se había unido a la congregación diez meses antes y no sólo había descubierto un nuevo propósito en la vida sino también una gran familia. Su repentina muerte tomó a todos por sorpresa. Las llamadas al consulado mexicano y a la patrulla de caminos de California no lograron gran cosa; carecía de documentos estadounidenses y mexicanos. Un hombre sin país. Legalmente ausente en una jurisdicción e ilegalmente presente en otra. Una carta sin enviar que se encontró entre sus magras pertenencias daba el domicilio de una añosa tía en Guadalajara, quien lo había dado por muerto muchos años atrás. Anticipando el relevo de esa tía en el poder legal, el pastor y algunas familias de la congregación asumieron la responsabilidad legal y financiera para la recuperación y el funeral del cuerpo de Efrén. Mientras el féretro descendía al foso en el cuidado cementerio del Valle del Silicón, ante las palabras de melancolía y esperanza del himno Más allá del sol, las mujeres de la congregación lloraban y se abrazaban. Después de la ceremonia, las hermanas se retiraron al comedor de la iglesia para servir la cena tradicional posterior a un funeral: pollo en mole. La repentina muerte del hermano Efrén conmovió profundamente y se conmemoró ritualmente y él — quien en su vida previa habría podido protagonizar uno de los oscuramente alarmistas anuncios en los medios por parte de Pete Wilson que decían «Siguen llegando»— sería echado de menos con gran dolor.

Dadas las lejanas posibilidades de un reconocimiento político formal para muchos como el hermano Efrén, nuestra exploración de la vida política y religiosa de los latinos ha de insistir: żfue el rescate, la inclusión y la dotación de poder de un trabajador marginal por parte de una comunidad marginal de fe de menor relevancia, que el compromiso formal de esa comunidad en los diversos niveles de la vida cívica? (Tras de su conversión, el hermano Efrén con frecuencia solicitaba y disfrutaba de la presentación de un himno de estilo ranchero: "Una llaga podrida era mi vida/ Y tirado en la basura/ Tú me encontraste»). Efectivamente, varios miembros de la congregación de Efrén participaban, activamente, en los esfuerzos 
comunitarios de las bases para combatir la obstructiva Propuesta 187. (Algunos servían como vínculo con las congregaciones afro-estadounidenses - la tarea se les daba fácilmente pues ellos, a diferencia de los activistas católicos, hablaban el mismo lenguaje religioso en una cadencia que resultaba familiar a la iglesia negra- Otros portaban habilidades musicales y de oratoria en público —-forjadas en los espacios de la iglesia-durante las marchas y manifestaciones en contra de la 187). Pero si los analistas políticos pueden comparar notas con los biógrafos de las personas y familias públicas, ciertamente podríamos equilibrar nuestras preocupaciones, por la voz y el comportamiento en la plaza pública, con una atención a las vidas interiores de las comunidades y personas marginales que habitan en plazas paralelas. El interior puede impactar el exterior. Con frecuencia, como Mordecai y su sobrina real Esther, quienes carecen de voz disputan, a quienes tienen reconocimiento formal, que hablen por ellos. El caso del hermano Efrén ofrece otro enérgico recordatorio en nuestra era de globalización económica. Ejemplifica, de manera aguda, la condición humana posmoderna: atomización, dislocación y fragmentación. Este escenario se da no sólo en las multitudinarias megaciudades y en los abandonados campos de los países subordinados, sino también en las vidas de millones de ciudadanos estadounidenses. A medida que se desintegra la plaza pública en una cacofónica multiplicidad de opciones digitales (aunque opciones controladas por intereses económicos cada vez más restringidos), las comunidades de fe de Estados Unidos pueden requerir enfocarse de manera más atenta a lo que Richard Shaull, el veterano teólogo de la liberación, ha caracterizado, en su estudio de los pentecostales brasileños, como «la reconstrucción de la vida humana comenzando por el nivel más básico» (Shaull y Cesar, 2000).

Para concluir, cuando se le mira ante el contraste de los caprichosos Estados-nación y las poderosas élites, ${ }^{6}$ la constancia del ethos y de la praxis de la solidaridad religiosa proletaria, captada en los testimonios ilegales, sugiere una visión alternativa de la política, al igual que un correctivo al duradero paradigma de las iglesias pentecostales latinas como enclaves sectarios sin compromiso. Una metodología expandida e interdisciplinaria habría de buscar estos rasgos.

\footnotetext{
${ }^{6}$ Los cambios en las políticas de inmigración (es decir, la repatriación masiva de un millón de mexicanos y mexico-estadounidenses durante la década de los treinta; el seductor Programa Bracero para trabajadores huéspedes de 1942-64; la punitiva Operation Wetback de los años cincuenta; las leyes de reforma migratoria de 1964, 1976, 1978, 1986 y 1998; las iniciativas tipo «chivo expiatorio» y las medidas de vigilancia así como penalización del cruce fronterizo de los años noventa) continúan como una maldición —o como una forma de fortalecer - a los políticos estadounidenses. A pesar de los abusos ampliamente documentados del Programa Bracero, el presidente George W. Bush ha expresado su inclinación a un gran incremento de los programas de trabajadores huéspedes, por encima de una amnistía general para los inmigrantes indocumentados (La Jornada, 17 de febrero de 2001). Acerca de la repatriación, véase Balderrama y Rodríguez (1995), y del Programa Bracero así como la Operación Espaldas Mojadas (Operation Wetback), Galarza (1977) y Samora (1971).
} 


\section{LA VOZ PÚBLICA EN LA DIÁSPORA}

"Guau, eres uno de los tres mexicanos de los que tengo noticia en todo el estado de Carolina del Norte», balbuceó el funcionario de alto rango del Departamento de Correccionales. Como parte de la gira de conciertos de los "gatos de callejón» de Yale (Yale Alleycats) en las vacaciones de primavera, nuestros huéspedes de la asociación de ex-alumnos programaron nuestro acto a capella frente a la primera audiencia realmente cautiva que teníamos: los presos de la prisión central de Raleigh. Nuestra tradicional mirada de estudiante de la Liga de Ivy intrigó a los funcionarios que ofrecían la cena de carne de res, previa al concierto. «ì h, de veras? », contestaba dubitativo. «żDónde están los otros dos?». "Aquí, justo debajo de nosotros», se rió, golpeando con su pie el piso del comedor de los guardias y gozando visiblemente de su sincronización. «Una pareja de jóvenes militares que se metieron en problemas».

El informe del censo estadounidense de 2000, respecto a más de 379 mil latinos en Carolina del Norte, estimulaba recuerdos como ése, de la última línea de un relato cómico. La explosión demográfica ha despertado un amplio interés por los últimos agentes de avanzada de una diáspora siempre en expansión, la que, al contrario de lo que dice la recomendación del conejo Bugs Bunny, está tomando directamente Albuquerque. Las fronteras ahora incluyen a Charlotte, Clinton, Durham... y Siler City. La parte etnográfica de este trabajo representa un intento inicial y modesto por describir la fe así como la práctica latina en esta nueva región, a la vez que sugiere comparaciones con espacios de colonización anterior.

Como otros académicos del «triángulo de la investigación», recibimos con agrado la oportunidad de estudiar algunas de las nuevas (y viejas historias) que se desarrollan en torno a nosotros. Fuimos en busca de peregrinos para husmear en sus oraciones, cantos y conversaciones, con la esperanza de plantear algunas preguntas acerca de la vida inmigrante, la fe y la solidaridad en Carolina del Norte.

Aunque en 1997 habíamos observado una marcha en honor de la Virgen de Guadalupe en el centro de Durham — con danzantes otomíes provenientes del Estado de México-, nos habíamos perdido, por muchos meses, el acontecimiento central de la historia católica latina en Durham, el éxodo airado de los latinos de la parroquia de la Santa Cruz, mayoritariamente afro-estadounidense. Los recién llegados se habían ofendido ante uno más de los muchos errores visibles del sacerdote (un cambio de horario para la misa bilingüe había resultado la gota que derramó el vaso) y abandonaron el templo en plena misa dominical, deteniéndose tan sólo para rescatar a la imagen de Nuestra Señora de Guadalupe del altar y transportarla a un lugar más hospitalario (The Herald Sun, 26 de octubre de 1997). La comunidad pronto fue recibida en una parroquia más amplia, en el centro de la ciudad, la Inmaculada Concepción.

Comenzamos nuestra investigación en el punto cero, en Durham, un lugar 
al que las grandes corporaciones hemisféricas, nacionales y regionales, se han ido a establecer de manera un tanto incómoda. En el lapso de unas cuantas semanas visitamos tres iglesias de la corriente dominante y una pentecostal; todas ellas habían iniciado «ministerios hispanos» entre uno y cuatro años antes. En una de las iglesias de la corriente dominante, encontré a un grupo huérfano de inmigrantes mexicanos (tres adultos y cinco niños) que se reunían en una sala de los grupos de afinidad durante la tarde, tras el servicio principal de la congregación, a las 11:00 de la mañana. La pequeña grey se trasladaba pacientemente por la sala, esperando a que llegara un pastor, el que fuera. Una pareja de la congregación anfitriona saludaba a quienes llegaban. Se les había asignado el papel de anfitriones para quienes llegaran por primera vez, pero planeaban irse antes de que concluyera el servicio. Finalmente, llegaron dos jóvenes guatemaltecos provenientes de Mount Olive, a una hora de viaje en automóvil desde el sureste. Pidieron disculpas por su retraso (éste era su segundo servicio del día) y por la ausencia de su ministro, luego procedieron a armar juntos un servicio. Más tarde, uno de ellos me informó que él partiría el martes hacia Chiapas, México, para unirse a su mujer, quien había comprado una casa y una tienda con las ganancias obtenidas en Carolina del Norte. Las inversiones servirían como base para el ministerio entre sus primos mayas. Según se colige de nuestra conversación, era obvio que la iglesia patrocinadora se olvidaba de los Billy Graham de piel morena, indígenas, en su seno. No obstante, la suya era la misma identidad transnacional que los investigadores del cambio religioso en México y de los procesos sociales de la migración, en ambos países, encontrarían sorprendente. Es claro que las variables religiosas han tenido un peso tan considerable (si no es que mayor) como el de las económicas en la intrépida decisión trinacional, de los evangelistas, de aumentar sus apuestas.

Una semana más tarde, y a unas cuantas cuadras de ahí, asistimos al servicio vespertino de otro ministerio de la corriente dominante. La jurisdicción regional de la denominación había ordenado al pastor, un graduado en divinidad de la Universidad de Duke, para ser ministro latino en 1997. Aquí, la cifra era del doble en comparación con la otra iglesia, con la misma proporción de niños y adultos. El pastor, un caribeño de piel clara casado con una mujer anglosajona, recibía ayuda de otra pareja anglosajona del seminario. La reunión se celebró en un cuarto que podía pasar por una capilla temporal. Había claras diferencias de clase entre los laicos y los clérigos. Los fieles, moderadamente alfabetos en español, todos mestizos de piel morena, estuvieron sentados, aunque inquietos, durante una liturgia y una homilía salpicadas de temas de liberación. Después del servicio, mientras las mujeres escogían prendas de un ropero de vestidos donados, el pastor se disculpó con nosotros por la escasa asistencia. «Venga el segundo domingo del mes. Se llena el templo para asistir a nuestra cena de cooperación culinaria».

Otro servicio de la corriente dominante, en la vecina Chapel Hill, presentó un conjunto completamente diferente de dinámicas de clase y género. La incorporación de vivaces coritos pentecostales hizo que el servicio transcurriera rá- 
pidamente. El sermón fue práctico y terrenal. Las diferencias de clase entre una pastora sudamericana (con un cónyuge anglosajón) y las varias familias de trabajadores - mexicanas y colombianas- parecía mitigarse por el terreno común de la experiencia femenina. Pero una mirada alrededor renovaría nuestras preguntas acerca de la marginación. Al relegar a los inmigrantes a los salones de grupos de afinidad y a las capillas laterales, muchas iglesias replican, sin darse cuenta, la especialidad alienante de la plaza pública.

Fue sólo durante una visita de parte del senador del estado de Louisiana y del klansman David Duke, en febrero de 2000, que nos sentimos atraídos a realizar una visita a Siler City, un pueblo a unos treinta minutos al sureste de Chapel Hill y a unos treinta años atrás en el «triángulo de la investigación». Yo había leído acerca de la iglesia bautista hispana en Love's Creek, del pastor mexicano de la iglesia y de un nuevo santuario en el periódico regional de izquierda Independent Weekly. La yuxtaposición de hostilidad racial xenófoba y la salvación de almas sin cuartel, en un pueblo de Tar Heel, resultaba demasiado irónica para resistírsele. Me encontré con una congregación compuesta por un grupo de personas muy decididas, quienes habían tomado posesión simbólica y física de doce acres de Tar Heel.

El servicio dominical matutino en la iglesia bautista hispana de Love's Creek, en la parte occidental de Siler City, se desarrolla en segmentos que se traslapan. Este domingo, a las 10:30, los alumnos de las diversas clases dominicales todavía recitaban de memoria sus versos de la semana frente a la congregación. Entramos a tiempo de escuchar al director de la escuela dominical indicar que los alumnos de la clase de los niños se reunieran al frente, para realizar su recitación. «La clase de los angelitos, entre comillas», dice en tono de broma. La congregación se ríe ligeramente con el chiste. El maestro de los angelitos, un joven de unos 22 años, confiesa tener ciertas dificultades para explicarles el verso a memorizar a los jóvenes a su cuidado. Incólumes, y sin darse cuenta de su embarazo, los siete alumnos recitan el séptimo mandamiento con un entusiasmo pulmonar, puntuando las sílabas en español para que su ejecución resulte más estética: «iNo cometerááásss adulteeerio!». Algunos miembros de la audiencia responden con un entusiasta «iAmén!» Varios se unen al aplauso y las enérgicas carcajadas. Otros sonríen ante la incongruente inocencia de los mensajeros. Otros más permaneces impasibles.

El mensaje directo acerca de la fidelidad se explica a través de la recitación, de los grupos de jóvenes y adultos, del consejo de San Pablo a los solteros, en el sentido de que se casen en vez de arder y a los casados de no negarse sus cuerpos entre sí, con excepción de la abstinencia mutua (Primera de Corintios, 15). Varios maestros presentan las recitaciones de su grupo al reconocer, públicamente, su gratitud ante Dios por sus esposas. Finalmente, el hermano Wilfredo, el director de la escuela dominical, invita a la hermana Verónica al facistol de pino, en forma de «I», para que comience el servicio de adoración.

La hermana Verónica, una adolescente de $1.60 \mathrm{~m}$ de altura, de unos 19 años de edad, se sitúa en una cómoda posición frente al facistol. Toma el micrófono 
cubierto de azul, que combina con el azul marino de su falda hasta el tobillo. Su bello rostro redondo y apiñonado está enmarcado por una diadema dorada y pequeños aretes de oro. Pide a la congregación que se ponga de pie para la lectura de la antífona, el Salmo 138. Dirige con una enunciación en cascada del texto en castellano de Reina y Valera: «Te alabaré con todo mi corazón; delante de los dioses te cantaré salmos». La congregación, basada también en su texto revisado de Reina y Valera, responde en un marcado unísono. Los versos 4 y 6 inspiran una vigorosa recitación: «Todos los reyes de la tierra te alabarán, Oh Señor [...] Porque el Señor es poderoso y atiende al humilde, pero el orgulloso sabe que está alejado». La asamblea de empacadores de carne, detalladores de muebles e inmigrantes parece gozar del prospecto de la llegada divina en la historia.

La hermana Verónica anuncia que la oración pastoral será dirigida por el reverendo Tapia. Se desliza detrás del teclado electrónico, en donde había estado moviendo algunos botones, se para junto al facistol, hace notar varias necesidades urgentes, celebra la milagrosa desaparición de la fiebre de un bebé durante la vigilia de oración de la noche anterior y luego, con su cara hacia la gente, cae de rodillas. Con los brazos levantados relata, dirigiéndose al cielo, los dolores y esperanzas de la congregación. Algunos fragmentos de su súplica sacerdotal son más audibles que otros por encima de las cabezas inclinadas: «Señor, qué deleitosos son los lugares en los que te encuentras [...] Continúa bendiciendo a tu pueblo [...] Te alabamos [...] Bendice a nuestros visitantes [...] Hazles sentir nuestros brazos que les dan la bienvenida, déjales saber que los amamos en Cristo». No se siente pretensión alguna en este pastor, quien muestra una figura un poco desaliñada en su traje gris de poliéster, su camisa blanca, su chaleco multicolor y sus gruesos anteojos que se deslizan a la mitad de su nariz y estimulan una profunda voz nasal. Su morena faz, gran quijada, junto con su cuerpo alto y fornido refuerzan su estatura como quien encabeza esta diminuta grey. Pero aquí, la distancia entre el clérigo y los laicos se zanja simplemente con una caricia o un abrazo.

La hermana Verónica pide al resto de los músicos que se unan al reverendo Tapia y al hermano Wilfredo en la plataforma. El toque de las cuerdas de tonos graves de la guitarra eléctrica puede oírse por debajo de su voz. El reverendo Tapia, quien regresa al doble teclado Roland, mueve otros cuantos botones y teclas. A la derecha del hermano Wilfredo, quien ahora ensaya, ligeramente, unos ritmos provenientes de las congas desde el nivel estomacal, toma a su hija, una adolescente que se ocupa de alinear las distintas partes del tambor en un confortable círculo alrededor de su banco. El bajista se para a su derecha. La hermana Verónica toma una pequeña pandereta sin forro. Un nuevo dirigente del cántico, quien aparenta acercarse a los treinta años de edad, toma un micrófono al otro lado de la hermana Verónica.

«Esta mañana ciertamente resultó romántica, i̇verdad?», comenta, todavía emocionado por el brillo nupcial del pasaje paulino. El comentario suscita una ligera risa en torno al santuario. Se lanza en un lento corito, cantado en una clave 
menor: «Gózateeeee delante de tu Señoooor», «Porque ÉEEEl es tu Rooocaaaaa». La joven del tambor marca las sílabas alongadas con largos golpes y secuencias del címbalo. La niña de tres años que está inmediatamente enfrente de la fila detrás de nosotros, vestida de rosa a la usanza de la pascua, sabe claramente qué ha de seguir. La novedad de nuestra presencia se ha desgastado. Se aleja, volteando a vernos a nosotros y a nuestro cuaderno de notas. Deja de pasearse entre las filas de sillas y se para entre sus padres, dirigiendo su rostro hacia el frente con ambos brazos levantados en excitada anticipación ante una señal familiar. Su primer aplauso corresponde, exactamente, con el comienzo de la disminución en el veloz ritmo de la versión recién cantada del coro. Sus rizos se mueven en contrapunto de su aplauso frenético. La segunda estrofa del coro, "El rey, el rey», resulta ser únicamente una corta unión con el siguiente coro: «Encienda el fuegooo. Encienda el fuegooo. Encienda el fuegooo de Dioooos». Se percibe un sentimiento marcadamente no-bautista en la música de aquí. El siguiente coro emprendido acaba de explicarlo. Una armonía familiar de Centroamérica: «ìQuién? (golpe de címbalo) ¿Quién? (golpe de címbalo) ¿Quién como Jehová? Que con su poder el mar abrió». Aunque Siler City está en un mundo y a muchas épocas de distancia del Mar Rojo, casi se puede ver a la hermana Verónica cruzar detrás de Miriam, que se aleja tocando y agitando la pequeña pandereta, entre los gritos y melodías de los recién emancipados esclavos hebreos. Dejamos nuestra furiosa escritura, metemos nuestro cuaderno de etnógrafo bajo el brazo y nos unimos a la celebración (más tarde podemos recordar la letra de las canciones y mejor aprovechamos una oportunidad que no podríamos gozar en la capilla de Duke). El cuarto coro también es familiar: «Echó a la mar (golpe de címbalo en «mar», luego dos golpes de percusión) el que perseguía (nota sincopada de 1/16 en la penúltima sílaba). Jinete y caballo echó a la mar. Echooó a la maaar los carros de Faraooón. iHey! iHey!» Las imágenes de un Hassidim, extasiado y girando, vienen a la mente.

Después de otros tres coros, la pequeña niña del tambor estira la medida final con una secuencia experta sobre los varios tambores y címbalos. Sigue un aplauso. Los «amén», «aleluya» $\mathrm{y}$ "gloria a Dios» tardan como un minuto en agotarse. (No está mal para los bautistas, pensamos). En conjunto, las salutaciones, testimonios, recitaciones, coritos y las exclamaciones espontáneas y en contrapunto de alabanza generan un universo de sonido, un espacio en donde lo divino puede intervenir en medio de un pueblo humilde.

El espacio no nos permite una descripción del sermón, la piedra angular de la liturgia bautista (el estilo del reverendo Tapia es quintaesencialmente bautista: expositivo y sencillo). Pero aquí, en Love's Creek, la comunidad ha situado a la prédica bautista dentro de un marco litúrgico pentecostal de su propia creación y con su propio significado.

En caso de que alguien se quede con la impresión de que se trata de una versión opiácea de lo religioso, la primera entrevista con los reverendos Israel y Ruth Tapia me sugieren que el poder divino invocado ese domingo puede durar hasta 
el sábado. Los Tapia me informaron que habían decidido ver la reunión de David Duke como algo en beneficio de sus fieles vulnerables. Había dos de los disconformes pertenecientes a un puñado de disidentes negros y latinos. Tras de que el gran mago (Grand Wizard) descendió los escalones del edificio del tribunal y a medida que atravesaba con la multitud, el reverendo Tapia le llamó «iDavid Duke!, iDavid Duke!» Cuando el provocador de hostilidades se volvió ante la voz, Tapia dio un mensaje que a la vez invitaba y desconcertaba: «iJesús te ama!» Ruth Tapia añadió una coda a la expresión de su esposo: «iSí, Jesús te ama y no le gusta lo que haces!» Quedó convencida de que la cara del hombre se caía de la vergüenza mientras se alejaba. Por su parte, el reverendo Tapia, un predicador bautista inmigrante de Chihuahua, siente que su tarea es crear un ambiente que inocule a los niños de la iglesia en contra de los David Duke, los faraones y los guardias de las prisiones del mundo. A juzgar por la apariencia y el sonido, muy probablemente podrían tener éxito.

Ruth Tapia nació en la miseria texana y conoció a su marido durante sus estudios misionales. La llamada a Carolina del Norte la tomó por sorpresa, pero la respuesta de su esposo ante ella no lo hizo. Por lo general, muestra su deferencia ante el perfil más público de su marido y, por ello, se alejó de los micrófonos de periodistas durante la manifestación de David Duke. Tales son las dimensiones del silencio - un silencio que no se articula y otro que actúa sobre uno mismo- en la plaza pública, en el propio país nativo. Se sintió especialmente lastimada por el ataque de un orador, durante la manifestación, en contra del ambivalente patriotismo de los latinos; ella recordó a varios veteranos chicanos (incluidos unos primos de ella) que regresaban a casa después de Vietnam. Expresó su admiración por los afro-estadounidenses, por sus luchas abolicionistas y por los derechos civiles. Poco después de nuestras entrevistas aceptó un empleo de vinculación con el programa wic del condado de Chatham. La encontramos meses más tarde, atendiendo una mesa de la fiesta del pueblo de la región en Chapel Hill. Mientras utiliza y afina las habilidades adquiridas en su comunidad eclesial de Texas y Carolina del Norte (la antesala de la plaza pública), Ruth Tapia muy pronto podría subir a la plataforma de la verdad para reclamar sus prerrogativas como ciudadana. Mientras tanto, sus interjecciones de estilo guerrillero, durante y en contra del discurso de David Duke, representan simplemente el comienzo de una serie de actos de habla, actos de habla que son congruentes con la identidad que su esposo pretende crear, interpelaciones que el Nuevo Sur tendrá que escuchar. ${ }^{7}$

Un acontecimiento más anticipaba este resultado, aunque de manera más

\footnotetext{
${ }^{7}$ "La interpelación es un acto de habla original, con el que el pobre se inserta en la comunidad real de la comunicación y de los productores (en nombre del ideal), y los hace responsables (accountable), exige un derecho universal, como ser humano que es parte de la comunidad; y, además, espera transformarla por medio de una praxis liberadora (la que con frecuencia también es una lucha), hacia una sociedad futura, posiblemente más justa» (Dussel, 1996).
} 
sutil que la manifestación de David Duke. En una entrevista previa, los Tapia confesaron haber permitido el paciente acceso de la música pentecostal, una decisión derivada de una desilusión previa con el pastorado de Siler City, con la deserción de los músicos hacia la Iglesia de Dios. Durante el servicio de dedicación del nuevo templo, la aproximación a la música al estilo «sensurround» pareció desconcertar a los cuarenta visitantes de las iglesias bautistas del área sureña (la asociación regional que había contribuido fuertemente al proyecto de construcción). Sin duda alguna, los modales sureños ayudaron a los visitantes a soportar la cacofonía. Pero lo que para observadores externos, pertenecientes a la corriente dominante, puede haber sonado como balbuceos litúrgicos, para alguien del interior —amamantado con la música evangélica negra y morena - sonaba como una dulce armonía, a la vez que para un etnógrafo, acostumbrado a significados no explícitos en la producción de sonidos y ritmos, era un seductor y rico texto cultural.

La música aportó un marco para la oposición al poder en el servicio de dedicación. La primera canción congregacional fue una expresión bilingüe importada de Suecia: "Qué grande eres», una canción tan usual cuyo debut por el músico solista dirigente, George Beverly Shea, del coro de Billy Graham, dejó la impresión incorrecta de que se trataba de una composición original estadounidense. Al principio, los músicos y los visitantes angloparlantes parecían fuera de sincronía entre sí. La subsiguiente sección en español suavizó la desigual disonancia. A partir de ello, las cosas fluyeron suavemente. Sin darse cuenta, los visitantes — varios de ellos eran «tembladores» $\mathrm{y}$ «movidos» en su pueblo, así como, probablemente, seguidores de Jesse Helms - se adaptaron al ritmo de bolero que los músicos, fieles a su memoria litúrgica, insistían en darle a la canción. De tal modo, un texto musical religioso que había sido exportado, ostensiblemente, hacia el sur de Estados Unidos décadas atrás, resurgía en un nuevo empaque a través de las tercas manos de los trovadores salvadoreños en el corazón del cinturón bíblico. En la construcción y mantenimiento de una identidad religiosa y cultural, los fieles de la iglesia bautista hispana en Love's Creek no ofrecían una tabula rasa para que escribieran en ella agentes más poderosos. En cambio, habían estado ocupados construyendo un ser (self), un ser que negociaba con el mundo más amplio. Nuestro estudio de ese proceso ha de continuar con una comprensión de estas etnopoéticas. Al utilizar el material y los recursos simbólicos disponibles, las emergentes comunidades latinas de fe optan por señales visibles propias, reclaman edificios, terrenos y respeto, al tiempo que llenan estos espacios con sonidos en busca de evocar, auditivamente, las imágenes del pasado y para recrear universos familiares (Connerton, 1989).

\section{CONCLUSIÓN}

Al abordar seriamente la práctica cultural de los creyentes latinos y describir, de manera densa, el curso de su vida en comunidad, llegaremos a una compren- 
sión más plena, de textura más rica, acerca de sus riesgos y ganancias desde su perspectiva en la intersección entre fe y vida cívica. Mientras que la evaluación cuantitativa de la participación civil ciertamente generará valiosos (y muy necesarios) índices del comportamiento y de las actitudes, seríamos negligentes, como estudiosos de este fenómeno, si no investigáramos también, profunda y creativamente, acerca de las cuestiones que surgen y que siempre han surgido, dentro de los corazones así como de las mentes de los peregrinos que todavía buscan su camino a Sión. Comprender el intento de una comunidad etnoreligiosa subalterna por establecer su propio espacio, por ejecutar su práctica cultural y por autorepresentarse puede requerir y sugerir algunos cambios de paradigma. Esos cambios serán bien recibidos.

BIBLIOGRAFÍA

Balderrama, Francisco E. y Raymond Rodríguez (1995), Decade of Betrayal: Mexican Repatriation in the 1930s, Albuquerque, University of New Mexico Press.

Brusco, Elizabeth (1995), The Reformation of Machismo: Evangelical Conversion in Colombia, Austin, University of Texas Press.

Burdick, John (1998), Blessed Anastacia: Women, Race and Popular Christianity in Brazil, New York, Routledge.

CONCEPCión, Juan (ed.), Ecos de vida: selección especial de himnos y canciones espirituales por compositores hispanos, Brooklyn, Editorial Ebenezer.

Connerton, Paul (1989), How Societies Remember, Cambridge, Cambridge University Press, pp. 6-40.

De la Garza, Rodolfo O., Louis DeSipio, F. Chris Garcia, John Garcia y Angelo Falcon (1992), Latino Voices: Mexican, Puerto Rican \& Cuban Perspectives on American Politics, Boulder, co, Westview Press, pp. 14, 58.

De la Garza, Rodolfo O. y Louis DeSipio (1993), "Overview: The Link Between Individuals and Electoral Institutions in Five Latino Neighborhoods», en Rodolfo O. de la Garza, Martha Menchaca y Louis DeSipio (eds.), Barrio Ballots: Latino Politics in the 1990 Elections, Boulder, co, Westview Press.

D'Epinay, Lalive (1969), Haven of the Masses: A Study of the Pentecostal Movement in Chile, Londres, Lutterworth P.

Durkheim, Emile (1970), Suicide: A Study in Sociology, Londres, Routledge.

Dussel, Enrique (1996), The Underside of Modernity: Apel, Ricoeur, Rorty, Taylor, and the Philosophy of Liberation, Eduardo Mendieta (trad. al inglés), Atlantic Highlands, NJ, Humanities Press International.

Erlmann, Veit (1996), Nightsong: Performance, Power, and Practice in South Africa, Chicago, University of Chicago Press.

Eschbach, Karl, Jacqueline Hagan, Nestor Rodríguez, Rubén Hernández-León y 
Stanley Bailey (1999), "Death at the Border», en International Migration Review, 33, vol. 2, verano, pp. 430-454.

Flores, William V. y Rina Benmayor (1997), "Constructing Cultural Citizenship», en William V. Flores y Rina Benmayor (eds.), Latino Cultural Citizenship: Claiming Identity, Space and Rights, Boston, Beacon Press.

Galarza, Ernesto (1977), Farm Workers and Agri-Business in California, 1947-1960, Notre Dame, University of Notre Dame Press.

Gill, Lesley (1994), Precarious Dependencies: Gender, Class and Domestic Service in Bolivia, New York, Columbia University Press.

Glock, Charles Y. (1958), The Role of Deprivation in the Origins and Evolution of Religious Groups, Berkeley, University of California Press.

Gorzueta, Roberto, Caminemos con Jesus: Towards a Hispanic/Latino Theology of Accompaniment, Maryknoll: Orbis Books, 1998.

Hernández Castillo, Rosalva Aída (2001), La otra frontera: identidades múltiples en el Chiapas poscolonial, México, Centro de Investigaciones y Estudios Superiores en Antropología Social.

Herrera-Sobek, María (1993), Northward Bound: The Mexican Immigrant Experience in Ballad and Song, Bloomington, Indiana University Press.

Martínez, Abelino (1989), Las sectas en Nicaragua: oferta y demanda de salvación, San José, Costa Rica, Editorial Departamento Ecuménico de Investigaciones.

Martínez, Jesús (1993), «Los Tigres de Norte en Silicon Valley», en Nexos, año 16, vol. XVI, no. 191, diciembre.

Ramírez, Daniel (1995), "Acknowledging a Borderless World», The Oakland Tribune, Oakland, CA, febrero 23.

Rosaldo, Renato y William V. Flores (1997), «Identity, Conflict, and Evolving Communities: Cultural Citizenship in San José, California», en Flores and Benmayor, pp. 57-96.

Samora, Julian (1971), Los Mojados: The Wetback Story, Notre Dame, University of Notre Dame Press.

Shaull, Richard y Waldo Cesar (2000), Pentecostalism and the Future of the Christian Churches: Promises, Limitations, Challenges, Grand Rapids, William B. Eerdmans.

Valverde, Jaime (1990), Las sectas en Costa Rica: pentecostalismo y conflicto social, San José, Editorial Departamento Ecuménico de Investigaciones.

Weber, Max (1970), "The Social Psychology of the World Religions», en H. Gerth y C.W. Mills (eds.), From Max Weber: Essays in Social Theory, Londres, Routledge.

Zlolniski, Christian (1998), «Reestructuración industrial y mano de obra inmigrante: el caso de los trabajadores mexicanos en la industria de la limpieza de edificios en el Silicon Valley, California», en Alfredo Lattes, Jorge Santibáñez y Manuel Ángel Castillo (eds.), Migración y fronteras, Tijuana, El Colegio de la Frontera Norte. 


\section{PERIÓDICOS}

«Durham Churches Reach Out to Hispanic Faithful» (1997), The Herald-Sun, Durham, NC, octubre 26.

«Soul and Skin: A Journey into the Triangle's Hispanic Heart» (2000), Independent Weekly, Durham, NC, enero 19-25.

«Hurricanes: The Storms of Latin America were not All Left Behind» (2000), Independent Weekly, Durham, NC, enero 26-1 de febrero.

«Fox y Bush acuerdan impulsar nueva política migratoria» (2001), La Jornada, México, febrero 17. 